\title{
KẾT QUẢ PHƯC HÌNH THẨM MỸ RĂNG TRƯớC SỬ DỤNG KỸ THUÂ̂T MẶT DÁN SỨ E.MAX TẠI MộT SỐ CƠ SỞ RĂNG HÀM MẶT
}

\section{TÓM TẮT}

Nghiên cứu được thực hiện trên 31 bệnh nhân có chỉ định phục hình thẩm mỹ̃ răng trước sử dụng kỹ thuật mặt dán sứ E.max đến khám và điều trị tại 1 số cơ sởRăng hàm mặt trên địa bàn Hà Nội trong khoảng thời gian từ tháng 7/2020 đến tháng 4/2021 nhằm đánh giá kết quả phục hình thẩm mỹ răng trước sử dụng kỹ thuật mặt dán sứ E.max. Đối tượng và phương pháp nghiền cứu: Là nghiên cứu mô tả kết quả lâm sàng không đối chứng, theo mô hình trước sau. Việc nghiên cứu được thực hiện trên 31 bệnh nhân với 96 đơn vị mặt dán sứ E.max, và kết quả, kết luận là: Sau khi phục hình mặt dán sứ E.max được thực hiện thu được tỷ lệ đánh giá mức độ tốt về hình thể là 92 đơn vị phục hình $(95,83 \%)$, màu sắc là 96 đơn vị $(100 \%)$, đường viền lợi là 94 đơn vi $(97,92 \%)$. Sau 3 tháng:hình thể, màu sẳc không thay đổi, đường viên lợi tăng lên với mức độ mức độ tốt $100 \%$.Độ bền, phát âm bình thường, chức năng nhai, sự hài lòng bệnh nhân là đạt $100 \%$

Tư khóa: Mặt dán sứ E.max, thẩm mỹ răng trước

\section{SUMMARY}

RESULTS OF AESTHETIC RESTORATION FOR INCISORS, CANINES AND PREMOLARS USTING E.MAX VENEER TECHNIQUE AT SOME STOMATOLOGIC CLINICS

The research was performed with 31 patients with aesthetic restoration for incisors, canines, and premolars using E.max veneer technique. These patients have checkup and treatment at some dental facilities in Hanoi from July 2020 to April 2021. The research is to assess results of aesthetic restoration for incisors, canines, and premolars using E.maxveneer technique. Research subject and method: the research of non-controlled clinical outcomes according to the pre and post model. The research was carried out on 31 patients with 96 E.max veneers. It is concluded that after E.max veneer restoration has been performed, the good assessment rate of appearance, color, and gingivalmargin are 93 restoration units $(95,83 \%), 96$ units $(100 \%), 94$ units $(97.92 \%)$ respectively. After three months, appearance and color are unchanged, gingivalmargin reaches $100 \%$ of goodness, viscosity and pronunciation are normal, and chewing function and patient satisfaction reach $100 \%$.

*Bệnh viện YHCT, Bộ Công An

**Bệnh viện RHM Trung ương, Hà Nội

Chịu trách nhiệm chính: Mai Văn Đức

Email: duchien39@gmail.com

Ngày nhận bài: 21/6/2021

Ngày phản biện khoa học: 10/7/2021

Ngày duyệt bài: 22/7/2021

\section{Mai Văn Đức*, Chu Thị Quỳnh Hương**}

Key words: E.max veneer, aesthetic restoration for incisors, canines, and premolars

\section{I. ĐẶT VẤN ĐỀ}

Ngày nay, với đời sống ngày càng cao, nhu cầu chăm sóc sức khỏe răng miệng ngày càng tăng lên và đặc biệt là nhu cầu về phục hình thẩm mỹ răng trước. Đối với những bệnh nhân có răng bị xấu về màu sắc, bất thường về hình thể, mất tổ chức cứng, lệch lạc mức độ nhẹ, bất cân xứng chiều cao các răng cửa cùng tên thì trước đây thường được chỉ định chụp sứ. Tuy nhiên việc điều trị bằng chụp sứ phải mài nhiêu mô răng, thay đổi cảm giác ăn nhai, dễ kích thích mô nha chu. Vì vậy kỹ thuật mặt dán sứ được thay thế với nhiều ưu điểm vượt trội là: mài răng ít, bảo tồn mô răng, đường viền cồ răng nguyên vẹn, tính thẩm mỹ cao, tương hợp tốt với mô mềm, bền vững trong thời gian dài, có những trường hợp không phải mài răng ${ }^{1,2,3,4,5}$

Hiện nay, cùng với sự phát triển của khoa học cồng nghệ, vật liệu sứ nha khoa ra đời với nhiều tên gọi khác nhau và ngày càng được cải tiến, sử dụng rộng rãi hơn. Đáng chú ý là sự ra đời của vật liệu sứ không kim loại Emax (hãng IVOCLA- VIVADENT). Thường được chỉ định trong phục hình các răng trước. So với vật liệu toàn sứ zirconia: khung zirconcó sự dẫn truyền ánh sáng kém hơn (khi sử dụng cho răng trước thường bị đục), không sử dụng etching và dán dính được ${ }^{6}$, trong khi đó thì sứ Emax khắc phục được nhược điểm này? dụng trong kỹ thuật mặt dán sứ răng trước

Ớ Việt Nam, hiện vật liệu sứ Emax đã được đưa vào sử dụng trong lâm sàng nhưng chưa có nhiều nghiên cứu, đặc biệt kỹ thuật sử dụng mặt dán sứ trong phục hình thẩm mỹ răng trước đã được tiến hành khá phổ biến trên lâm sàng nhửng có rất ít nghiên cứu đánh giá kết quả về kỹ thuật này. Vì vậy chúng tôi chọn đề tài nghiên cứu: "Kết quả phục hình thẩm mỹ răng trước sử dụng kỹ thuật mặt dán sứ Emax tại một số cơ sở Răng HàmMặt"với 2 mục tiêu:

- Mục tiều 1: Mô tả đặc điểm lâm sàng, cận lâm sàng của các bệnh nhân được chỉ định phục hinh thẩm mỹ răng trước sử dụng kỹ thuật mặt dán sứ Emax tại một số cơ sở Răng Hàm Mặt trên đỉa bàn Hà Nôi năm 2020-2021

- Mục tiêu 2: Nhận xét kêt quả phục hình thẩm mỹ răng trước sử dụng kỹ thuật mặt dán 


\section{sứ Emax cho nhóm bênh nhân trên}

\section{II. ĐỐI TƯợNG VÀ PHƯƠNG PHÁP NGHIÊN CỨU 1.Đối tượng}

- Tiêu chuẩn lựa chọn: Tất cả những bệnh nhân có chỉ định phục hình thẩm mỹ răng trước sử dụng kỹ thuật mặt dán sứ, đến khám và điều trị tại khoa phục hình bệnh viện răng hàm mặt trung ương Hà Nội, trung tâm nha khoa 225 Trường Chinh -Viện Đào Tạo Răng Hàm Mặt từ tháng 7/2020 đến tháng 4/2021.

- Tiêu chuẩn loại trừ: Bệnh nhân có thói quen xấu tạo nên các lực quá lớn trên phục hình, bệnh nhân có vấn đề về tâm lí không hợp tác với bác sĩ, bệnh nhân không có điều kiện để kiểm tra theo dõi đánh giá theo lịch hẹn. Các răng trước có chống chỉ định sử dụng kỹ thuật mặt dán sứ.

\section{Phương pháp}

- Là một phương pháp nghiên cứu mô tả kết quả lâm sàng không đối chứng, theo mô hình "trước-sau"

- Thời gian nghiên cứu: Từ tháng 7/2020 đến tháng 4/2021. Trong nghiên cứu của chúng tôi số lượng răng nghiên cứu là 96 răng

- Phương pháp tiến hành:

+ Nguyên tắc: Bảo tồn men răng tối đa (có trường hợp không phải mài răng), có bộ mũi khoan kim cương để mài sửa soạn chuyên biệt, lựa chọn kiểu mặt dán sứ, mài mặt bên và mài ria cắn, tạo được sự ổn định ban đầu, phục hồi thân răng trước khi làm mặt dán sứ, phục hình tạm thẩm mỹ khi chờ gắn mặt dán sứ

+ Các bước tiến hành: Lây dấu, đổ mẫu nghiên cứu và ghi tương quan hai hàm bằng sáp ở khớp cắn trung tâm, lên kế hoạch điều trị, làm Wax-up sáp, làm Mock-up trền miệng bệnh nhân, mài sửa soạn cho phục hình mặt dán sứ, đă̆t chi co nướu,so màurăng và gửi labo, làm răng tạm, gắn phục hình

*Wax-up sáp: làm Wax up sáp trên mẫu đã được điều chỉnh, Wax-up sáp sẽ đinh hình trước hình dạng và đô dày của mặt dán sứ sau này. Lấy dấu khóa mẫu đã được làm Wax up bằng silicon (lấy 2 mẫu: mẫu 1 để làm mock-up và răng tạm, mẫu 2 dùng để làm dấu khóa silicon để kiểm tra mức độ mài răng khi mài cùi)

* Sử dụng dấu silicon đầu tiên cho nhựa làm răng tạm và đặt vào cung răng bệnh nhân, khi vật liệu nhựa tạm đã trùng hợp hết thì lấy dấu silicon ra cẩn thẩn, loại bỏ nhựa thừa bằng dụng cụ thích hợp, giữ lại dấu silicon để sau khi mài cùi làm răng tạm, lúc này ở trên miệng chính là mô phỏng mặt dán sứ chính thức sau này

*Trong trường hợp mặt dán sứ bắt buộc phải sữa soạn răng thì sẽ tiển hành sửa soạn như sau: đặt chỉ co nưỡu để bảo vệ lợi, đặt matrix để trách tổn thương răng kế cần, xác định đô sâu cần mài bằng mũi mài đánh dấu, mài mặt ngoài $0.3-0.7 \mathrm{~mm}$ men răng bằng mũi khoan đánh dấu với 2 bình diện giải phẩu răng, dùng mũi khoan kim cương trụ thuôn để mài hoàn tất, dùng dấu khóa làm từ mẫu silicon thứ 2 để kiểm tra độ dày đã mài,mài đường hoàn tất bờ cong, trên, ngang hoăcc dưới lợi, làm tròn các góc. Mài mặt bên theo nguyên tắcbảo toàn điểm tiếp giáp khi không có khe thưa và ngược lại, đường hoàn tất bờ cong. Mài rìa cắn: loại cửa sổ và Feathe không mài hạ thấp rìa cắn, loại Butt margin mài rìa căn $0,5-1 \mathrm{~mm}$, loại phủ một phần mặt trong thì mài rìa cắn $2 \mathrm{~mm}$ và một phần mặt trong

*Gắn phục hình: Thử phục hình, chuẩn bị bề mặt trong của mặt dán sứ, chuấn bị bề mặt răng. Cách ly các răng bên cạnh bằng teflon, cho Ciment Variolink vào mặt dán đặt lên mặt răng,lấy hết chất gắn thừa bằng chỉ tơ nha khoa, chiếu đèn quang trùng hợp

*Mă̆t dán sứ E.max sau khi được gắn sẽ được kiểm tra và hoàn thiện

3. Xử lý số liệu: Sử dụng phần mềm thống kê y học SPSS 20.0 với các thuật toán mô tả tỷ lệ với mức ý nghĩa thống kê $p<0,05$

4. Đạo đức nghiên cứu: Nghiên cứu tuân thủ đầy đủ các nguyên tắc đạo đức của nghiên cứu y học. Bệnh nhân tự nguyện tham gia nghiên cứu, các thông tin liên quan bệnh nhân được bảo mật

\section{KẾT QUẢ NGHIÊN CỨU}

Kết quả ngay sau khi phuc hình răng trước bằng mặt dán sứ E.max được đánh giá về mặt thẩm mỹ với 3 tiêu chí: hình thể, màu sắc, và đường viền lợi của răng phục hình được trình bày ở bảng 1 . Về hình thể với tổng số 96 đơn vị phục hình thì 92 đơn vị đat mức đô tốt (chiếm $95,83 \%$ ), màu sắc đẹp đạt $100 \%$, đường viên lợi đạt mức độ tốt 94 đơn vị phục hình (chiếm $97,92 \%)$.

Bảng 1. Đánh giá kêt quả phục hồi thẩm mỹ theo vị trí nhóm răng sau phục hình

\begin{tabular}{|c|c|c|c|c|c|c|c|c|c|c|}
\hline \multirow{3}{*}{ Tiêu chuẩn đánh } & \multicolumn{4}{|c|}{ Răng cửa \& Răng nanh } & \multicolumn{4}{|c|}{ RHN } & \multicolumn{2}{|c|}{ Tống số } \\
\hline & & & & & & ót & & & & \\
\hline & SL & $\%$ & SL & $\%$ & SL & $\%$ & SL & $\%$ & SL & $\%$ \\
\hline Hình thế & 85 & 88,54 & 3 & 3,13 & 7 & 7,29 & 1 & 1,04 & 96 & 100 \\
\hline
\end{tabular}




\begin{tabular}{|c|c|c|c|c|c|c|c|c|c|c|}
\hline Màu sắc & 88 & 91,67 & 0 & 0 & 8 & 8,33 & 0 & 0 & 96 & 100 \\
\hline Đường viền lợi & 86 & 89,59 & 2 & 2,08 & 8 & 8,33 & 0 & 0 & 96 & 100 \\
\hline
\end{tabular}

Theo dõi sau 3 tháng phục hình được trình bày ở bảng 2, gôm các tiêu chí:

- Tỷ lệ đẹp về hình thể là không thay đổi

- Tỷ lệ đẹp về màu sắc là không thay đổi

- Tỷ lệ đường viện lợi mức độ tốt tăng lên và đạt $100 \%$

Bảng 2. Đánh giá kết quả phục hồi thẩm mỹ theo vị trí nhóm răng sau 3 tháng

\begin{tabular}{|c|c|c|c|c|c|c|c|c|c|c|c|c|c|c|}
\hline \multirow{3}{*}{$\begin{array}{c}\text { Tiêu } \\
\text { chuẩn } \\
\text { đánh giá }\end{array}$} & \multicolumn{6}{|c|}{ Răng cửa \& Răng nanh } & \multicolumn{6}{|c|}{ RHN } & \multicolumn{2}{|c|}{ Tống số } \\
\hline & \multicolumn{2}{|c|}{ Tốt } & \multicolumn{2}{|c|}{ TB } & \multicolumn{2}{|c|}{ Kém } & \multicolumn{2}{|c|}{ Tốt } & \multicolumn{2}{|c|}{ TB } & \multicolumn{2}{|c|}{ Kém } & & \\
\hline & $\mathbf{S L}$ & $\%$ & $\mathbf{S L}$ & $\%$ & SL & $\%$ & SL & $\%$ & $\mathbf{S L}$ & $\%$ & $\mathbf{S L}$ & $\%$ & SL & $\%$ \\
\hline Hình thế & 85 & 88,54 & 3 & 3,13 & 0 & 0 & 7 & 7,29 & 1 & 1,04 & 0 & 0 & 96 & 100 \\
\hline Màu sắc & 88 & 91,67 & 0 & 0 & 0 & 0 & 8 & 8,33 & 0 & 0 & 0 & 0 & 96 & 100 \\
\hline Đường viền lợi & 88 & 91,67 & 0 & 0 & 0 & 0 & 8 & 8,33 & 0 & 0 & 0 & 0 & 96 & 100 \\
\hline
\end{tabular}

Kết quả sau 3 tháng phục hình:

- Tất cả 96 đơn vị phục hî̉nh đều có tổ chức quanh răng tốt, không sẩu răng, không ê buốt, không bị nhạy cảm bởi các kích thích, chụp X. quang hoàn toàn bình thường

-Tất cả 31 bệnh nhân nghiên cứu đều có tổ chức quanh răng bình thường

-Tất cả các đơn vị phục hình sau 3 tháng không có hiện tượng sứt mẻ sứ, vỡ sườn, bong mặt dán. Kết quả cũng cho thấy không có sự

khác biệt về độ bền của phục hình mặt dán sứ Emax đối với vùng răng cửa, răng nanh, răng hàm nhỏ

Theo dõi sau 3 tháng phục hình được trình bày ở bảng 3 , gôm các tiêu chí chức năng nhai và sự hài lòng của bệnh nhân:

- Tất cả các rằng phục hình đều có chức năng nhai bình thường

- Tất cả các răng phục hình bệnh nhân đều hài lòng

Bảng 3. Đánh giá kêt quả phục hồi chức năng nhai và sự hài lòng của bệnh

\begin{tabular}{|c|c|c|c|c|c|c|c|c|}
\hline \multirow{2}{*}{ Tiêu chí đánh giá } & \multicolumn{3}{|c|}{ Tốt } & \multicolumn{2}{c|}{ Trung bình } & \multicolumn{2}{c|}{ Kém } & \multicolumn{2}{c|}{ Tống số } \\
\cline { 2 - 9 } & SL & $\mathbf{\%}$ & SL & $\mathbf{\%}$ & SL & $\mathbf{\%}$ & SL & $\mathbf{\%}$ \\
\hline Chức năng nhai & 96 & 100 & 0 & 0 & 0 & 0 & $\mathbf{9 6}$ & $\mathbf{1 0 0}$ \\
\hline Sự hài lòng của bệnh nhân & 96 & 100 & 0 & 0 & 0 & 0 & $\mathbf{9 6}$ & $\mathbf{1 0 0}$ \\
\hline
\end{tabular}

\section{BÀN LUÂ̂N}

Kết quả sau phục hình được đánh giá tại hai giai đoạn, ngay sau khi phục hình được thực hiện và sau phục hình 3 tháng

Ngay sau khi phục hình:

- Hình thể phục hình: Hình thể bên ngoài của mặt dán sứ E.max được đánh giá là rất tốt, với tổng số 96 đơn vị phục hình thì chỉ có 4 đơn vị phục hình (chỉ chiếm 4,16\%) được đánh giá hình thể ở mức trung bình nhưng chấp nhận được về mặt thẩm mỹ (do hình thể răng bên cạnh không thuận lợi), số còn lại đều có hình thể tốt

- Đánh giá về mức độ tốt của đường viền lợi cho các đơn vị phục hình thì chỉ có 2 đơn vị có đường viền lợi ở mức trung bình, số còn lại đều tốt.

- Màu sắc được đánh giá đẹp giống như màu sắc răng tự nhiên là 96 đơn vị phục hình chiếm 100\% (tất cả các bệnh nhân đều được tem màu tại labo). Màu sắc của phục hình tự nhiên giống răng thật, hài hoà với các răng trển cung hàm, phục hình có tính dẫn truyền ánh sáng như răng tự nhiên, có độ trong mờ, có hiệu ứng phát huỳnh quang. Trên tổng thể hàm răng được phục thẩm mỹ răng trước bằng mặt dán sứ E.max có được sự hài hoà, sống động tự nhiên khi nhìn vào.

\section{Sau phục hình 3 tháng:}

- Những yếu tố sau 3 tháng phục hình không thay đổi là: Phát âm, khớp cắn, thẩm mỹ chung, hình thể phục hình. Đây cũng là những yếu tố ít thay đổi theo thời gian

- Việc đánh giá độ bền của một phục hình phải thực hiện sau một thời gian dài theo dõi, tuy nhiển do thời gian thực hiện đề tài có hạn, chúng tôi chỉ đánh giá được sau 3 tháng điều trị. Đây là một trong những hạn chế của nghiên cứu này. Trong nghiên cứu này với tổng số 96 đơn vị phục hình thực hiện cho 31 bệnh nhân, chúng tôi khổng phát hiện bất kỳ trường hợp nào bị rạn, nứt, vỡ sứ. Do đó độ bền của phục hình là $100 \%$ ở cả hai nhóm răng cửa, răng nanh và răng hàm hàm nhỏ.

Tuy nhiên theo Nghiên cứu của Peumans $M$, Van Meerbeek B, Lambrechts P, Vuylsteke Wauters M, Vanherle $G$ năm 1998 về 87 veneer sứ được đặt ở răng trước trên 25 bệnh nhân trong 5 năm thì có

- Tình trạng răng trụ: Đối với răng phục hình có tủy sông không có trường hợp nào bị kích thích tủy, không có viêm tủy. Không có răng trụ 
nào bị lung lay, trên hình ảnh XQ so với ngay sau khi lắp phục hình xương ổ răng không bị tiêu, không có hiện tượng sâu răng thứ phát ở bờ phục hình hoặc cổ răng.

- Đường hoàn tất phục hình, tiếp xúc phục hình với răng bên cạnh không thay đổi sau 3 tháng.

- Đường viền lợi của răng phục hình là rất tốt sau 3 tháng đạt $100 \%$ mức độ đẹp về hình thể và màu sắc (tăng thêm 2 đơn vị phục hình từ trung bình lên tốt). Đó là do sau 3 tháng phục hình bệnh nhân đã biết cách vệ sinh răng miệng và thích nghi với sự hiện diện của phục hình

- Sau phục hình 3 tháng chức năng nhai đạt mức độ tốt là $100 \%$ (tăng lên) do có 2 bệnh nhân đã thích nghi với phục hình mới

- Sự hài lòng của bệnh nhân sau phục hình 3 tháng vẫn là $100 \%$

\section{KẾT LUẬN}

- Ngay sau khi phục hình cho thấy, tỷ lệ thành công đẹp về hình thể, màu sắc, đường viên lợi là rất cao: hình thể với $95,83 \%$, màu sắc với $100 \%$, đường viền lợi với 97,92\%.

- Sau lắp phục hình 3 tháng các tiêu chí đẹp về hình thể và màu sắc là không thay đổi, tiểu chí đường viền lợi thậm chí còn tăng lên

- Về chức nằng: $100 \%$ bệnh nhân có chức năng ăn nhai và phát âm không bị ảnh hưởng

- Độ bền: Không có trường hợp nào bị mẻ sứ, võ sườn, bong mặt dán trong thời gian theo dõi 3 tháng

- Sau 3 tháng tình trạng vùng quanh răng và tình trạng răng trụ đều rất tốt, không có trường hợp nào có phục hình làm ảnh hưởng đến răng trụ và tổ chức quanh răng

- 100\% bệnh nhân đều hài lòng với kết quả phục hình

\section{TÀI LIÊU THAM KHẢO}

1. Sheets CG,Taniguchi T.Advantages and lamitations in the use of porcelain veneer restorations. J prosthet Dent.1990;64(4):406411.doi:10.1016/0022-3913(90)9035-6

2. Strassler HE.Minimally invasive porcelain veneers:indications for a conservative esthetic dentistry treatment modality. Gen Dent.2007; 55(7): 686-712

3. Fradeani M, Redemagni M.,Corrado M.Porcelain laminate veneers:6-to 12-year clinical evaluation- A RetrospectiveStudy. International Journal of Periodontics andRestorative Dentistry. 2005; 25(1):9-17

4. Chu Thị Quỳnh Hương (2010). Nghiên cứu và đánh giá kết quả sử dung vât liêu toàn sứ IPS Empress 2 trong phục hình nhóm rằng trước, Luận văn tiến sĩ y học, Trường Đại Học Y Hà Nội

5. Nobrega A.S., Silva Signoreli A.F. Quinelli Mazzaro J.V., Zavanelli R.A., Zavanell A.C.Minimally invasive preparationss:contact lenses.Journal of Advanced Clinical\&Research Insights.2015;2:176-179.

6. Brodbelt RHW, O'Brien WJ, Fan PL (1980). "Translucency of dental porcelain". J Dent Res. Pp.59:70

7. Willard A, Gabriel Chu TM. The science and application of IPS .Max dental ceramic. Kaohsiung] Med Sci. 2018;34(4):238-242. doi: 10.1016/j.kjms.2018.01.012

8. Peumans $M$, Van Meerbeek $B$, Lambrechts $P$, Vuylsteke- Wauters M, Vanherle G . Five-year clinical perfomance of porcelain veneers. Quintessence int . 1998;29(4):211-221

\section{NHÂ̂N XÉT THỰC TRANG CHĂM SÓC NGƯỜI BỆNH TOÀN DIỆN TẠI BÊ̂NH VIÊ̂N ĐA KHOA HÒA BÌNH - THÀNH PHỐ HẢI DƯO'NG NĂM 2018}

\section{TÓM TẮT}

Mục tiêu: Nhận xét thực trạng những yếu tố ảnh hưởng đến chăm sóc người bênh toàn diên (CSNBTD); Đề xuất một số giải pháp để tăng cường công tác CSNBTD cho người bệnh (NB) tại Bệnh viện Đa khoa Hòa Bình - Thành phố Hải Dương năm 2018" Đối

*Trường Đại học Thành Đông;

**Trướng Đai học Y tế Công cộng

Chịu trách nhiệm chính: Phạm Thị Nhuyên

Email: bongtuyet1104@gmail.com

Ngày nhận bài: 4/6/2021

Ngày phản biên khoa hoc: 29/6/2021

Ngày duyệt bài: 21/7/2021

\section{Phạm Thị Nhuyên*, Trần Trọng Hải** Nguyễn Đức Sơn*, Nguyễn Thu Hà*}

tượng và phương pháp: Nghiên cứu mô tả cắt ngang 74 điêu dưỡng $(\mathrm{DD})$ tham gia CSNBTD và 368 người bệnh, người nhà trực tiếp tham gia chăm sóc người bệnh: tại Bệnh viện Đa khoa Hòa Bình - Thành phố Hải Dương năm 2018. Kết qủa và kết luận: Người Điều dưỡng đã thực hiện tốt các nhiệm vụ cửa minh, gồm: đón tiếp, chằm sóc, cấp cứu, hướng dẫn NB cách chế biến thức ăn, chế độ ăn và cho ăn... Nắm vững diễn biến bệnh của $\mathrm{NB}$, báo cáo kịp thời với bác sĩ. Thực hiện một số công tác vô khuẩn khác đạt tới $100 \%$ so với điểm chuẩn. Trong quá trình thực hiên CSNBTD, điều dưỡng đã nhận được sự quan tầm của các cấp lãnh đạo bênh viện, lãnh đạo k̉hoa, các phòng ban chức năng phổi hợp kiểm tra đôn đốc kịp thời và $100 \%$ Điêu dưỡng được tập huấn quy trình chăm sóc 